\title{
Trust in School Principals: Teachers' Opinions
}

\author{
Aydin Balyer $^{1}$ \\ ${ }^{1}$ Faculty of Education, Yildiz Technical University, Turkey \\ Correspondence: Aydin Balyer, Faculty of Education, Yildiz Technical University, Turkey. E-mail: \\ balyer@yildiz.edu.tr
}

Received: March 18, 2016

Accepted: December 27, 2016

Online Published: April 4, 2017

doi:10.5539/jel.v6n2p317

URL: http://doi.org/10.5539/jel.v6n2p317

\begin{abstract}
Trust is considered as one of the essential elements at schools. Although it is important, there is relatively little research on trust in educational settings. Research indicate that trust across school affects much of a school's functioning and it is a critical resource as principals embark on improvement plans. In this regard, it is a matter of question whether teachers trust in their principals as school leaders, in their administrative implementations and in their principals' personalities. Therefore, this qualitative study purposed to discover teachers' opinions on their trust in their school principals. Results reveal that teachers of this sample do not trust in their principals in all sub-themes in general. It can be concluded that there is a lack of trust in their principals in all sub-themes among teachers at schools. It is recommended that principals should be chosen and appointed to their posts with a more careful way.
\end{abstract}

Keywords: school principals, teachers, trust

\section{Introduction}

The term "trust" has been considered as one of the essential elements in schools. Despite its importance, there is relatively little research on trust. These researches indicate that trust across school affects teachers, its functions and administrators. It also separates effective schools from ineffective ones (Tarter, Sabo, \& Hoy, 1995; Bryk \& Schnider, 2002). According to Goddard, Tschannen-Moran, and Hoy (2007) trust makes schools better places for students to learn, teachers to teach and administrators to manage. They reveal a positive relationship between trust and school outcomes (Tschannen-Moran, 2004b). Bryk and Schneider (2003) indicate that trust does not guarantee success alone. However, schools have no or little chance to improve when there is no trust there.

\section{Trust in School Principals}

Trust in the principal is defined as, "the teachers' confidence that the principal will keep his or her promise and act in the best interest of the teachers (Hoffman, Sabo, Bliss, \& Hoy, 1994; Hoy \& Kupersmith, 1985; Tarter et al., 1995). Trust means faith in and loyalty to the leader in an organization (Ngodo, 2008). Hoy and Tschannen-Moran (2003) put that trust "is an individual's or group's willingness to be vulnerable to another party based on the confidence that the latter party is benevolent, reliable, competent, honest, and open". In this respect, while benevolence means confidence that one's well-being will be protected by trusted party, reliability means the extent to which one can count on another person or group. Similarly, while competency means the extent to which the trusted party has knowledge and skill and honesty means the character, integrity, and authenticity of the trusted party, openness means the extent to which there is no withholding of information from others. When school setting is considered, trust has four aspects including trust in colleagues, principal, student and parent. Of these aspects, teacher's trust in principal is essential and basis of trust in schools (Hoy \& Tschannen-Moran, 2003). They believe that teachers' trust in principal is based on their willingness to depend on principal as he/she is perceived as reliable, kind, honest and trustworthy.

Marlowe and Nyhan (1997) put these elements as trustworthiness, faith and loyalty to the leader, which is considered as the basis for studying trust in educational settings. Trust in the principal was determined by the behavior of the principal and faculty trust in colleagues was determined primarily by the behavior of teachers (Tschannen-Moran \& Hoy, 1998). It is considered that different factors are directly influential in teacher trust in principal/leader (Bass \& Riggio, 2006; Dirks \& Ferrin, 2002; Gillespie \& Mann, 2004; Jung \& Avolio, 2000; Mitchell, Kensler, \& Tschannen-Moran, 2010; Pillai, Schriesheim, \& Williams, 1999; Podsakoff, MacKenzie, 
Moorman, \& Fetter, 1990; Tschannen-Moran, 2003; Tschannen-Moran \& Goddard, 2001; Zeinabadi \& Rastegarpour, 2010).

Trust and leadership dimensions that support empowerment and involvement will predict an educational organization's ability to minimize a threat-rigid response and flexibly negotiate new demands (Daly, 2009). Trust alone emerged as an important factor in relation to greater citizenship among teachers, which is significant because to meet the challenging new standards that have been set for schools, school personnel must go well beyond minimum performance of their duties. Therefore, school leaders need to know what is necessary to foster these extra-role behaviors (Tschannen-Moran, 2003). Tschannen-Moran (2009) also found that trust plays a strong role especially in faculty perceptions of the professionalism. In this respect, faculty trust in colleagues and the professional orientation of the principal were found to make an independent contribution to explaining teacher professionalism, while faculty trust in the principal and faculty trust in students and parents played a moderating role. For this reason, schools should foster greater teacher professionalism by exercising their administrative authority with a professional orientation and adopting practices that lead to strong trust among school leaders, teachers, students, and parents.

Although significant relations were found between staff performance and trust in administrators' behaviors in non-educational settings, there are few resources conducted to discover what their thoughts on their trust in their principals in educational settings. For this reason, the main purpose of this study is to determine if teachers trust in their principals as school leaders, their principals personally, their principals' administrative daily implementations.

\section{Method}

This study employed a qualitative research design which is usually used to gain in-depth knowledge in a study (Denzin \& Lincoln, 2005; Marshall \& Rossman, 2006). Creswell (2002) described these researches as "are qualitative research procedures for describing, analyzing, and interpreting a culture-sharing group's shared patterns of behavior, beliefs, and language that develop over time." As such, by using this research design and utilizing in-depth interviews, the study discovered "culture-sharing" behaviors, beliefs, and language among teachers in Turkey. Teachers' views were gathered by means of interviews with semi-structured questions. The research has mainly sought answer to the following question: "How do you evaluate your trust in your school principal in terms of trust in your principal a as school administrator, in their administrative implementations and in your principals' personality in general?"

\subsection{Participants}

The participants of this study were 30 teachers from Beşiktaş, Kadıköy and Esenler Townships in İstanbul, Turkey in the 2015/2016 academic year. They were chosen with criterion sampling as a feature of purposive sampling method which means forming the working group from the ones with similar characteristics (Bailey, 1994). In purposive sampling, personal judgment needs to be used to choose cases that help answer research questions or achieve research objectives. Therefore, the reason for choosing these teachers is that they are the ones who can describe trust in their principals in their schools. Of the participants, 18 were males, 12 females. While 9 teachers have 6-10 years' experience, 11 have 11-15, 5 have 16-20 and 5 have more than 20 years experience. As 23 teachers have graduate degrees, 7 have post graduate degrees.

\subsection{Data Collection and Analysis}

In this research, the data were collected using the "repertory grid" technique, which can best be characterized as a semi-structured interview. This technique is an instrument designed to capture the dimensions and structure of personal meaning. It is not so much a test in the conventional sense of the word as a structured interview designed to make those constructs with which persons organize their world more explicit. Rather, its aim is to describe the ways in which people give meaning to their experience in their own terms (Feixas \& Cornejo, 2002). Here, the respondent is confronted with a triad of elements and then asked to specify some important way in which two of the elements are alike and, thereby, different from the third (Kerkhof, 2006). In this respect, the researcher visited teachers were e-mailed to inform them about the purpose of the study. 35 teachers volunteered to participate in the research and 30 out of 35 were invited for the interview. The five volunteers were excluded because they waived from the research themselves. They were consented after being assured of the confidentiality of the data to be gathered from them. It was promised that their identities would be kept in secret and their names would not be mentioned in any part of the study or shared with anyone else. Second, an interview was planned on an agreed-upon day, and the participants were visited on that date. The interviews were both recorded and written down with their permission and each took approximately 30-40 minutes. 
The data were analyzed with "content analysis" technique which usually aims to gather similar data on a topic and comment on (Mayring, 2000). The first step taken in the analysis of the data was the data organization procedures recommended by Bogdan and Biklen (1998). These are category definition, exemplification, and codification regulation. Here, the questions were conceptualized and named with some separate statements such as trust in principals as school administrators, trust in their administrative implementations, and trust in their principals' personality. In the second step, the conceptualized statements were brought together. In the third step, it was intended to avoid repetition. In the last phase, the identified results were explained and related to each other by building a cause-and-effect relationship among the separate parts. The perceptions of teachers on trust in principals were coded as $\mathrm{T} 1, \mathrm{~T} 2 \ldots$ The research was conducted mainly with the following semi-structured questions developed by the researcher himself:

1) "How do you evaluate your trust in your school principal in terms of trust in your principal a as school administrator?" If so why, why not?

2) Do you trust your school principal in his/her administrative implementations? If so why, why not?

3) As far as your principal's personality is concerned, do you trust your school principal? If so why, why not?

\subsection{Trustworthiness and Rigor}

Here, the interviewer played the role of facilitator and listener by simply asking questions and recording the answers without leading them. The questions were reviewed by six field experts to ensure content validity. The latest forms of the questions were developed with these experts' suggestions. In addition, the teachers were content enough with the confidentiality of the research to get in-depth answers without any hesitation. The locations were chosen to avoid being affected by power relations. The participants were interviewed somewhere out of the school buildings since they may have some hesitations to be disgraced by their principals. Therefore, interviews were organized and conducted somewhere out of the school building. Some precautions were taken to ensure the validity and reliability of the study.

a. While preparing interview form, the related literature was examined to create a contextual frame in order to increase the internal validity of the research. Member checking was also done. Moreover, participants were able to express their opinions freely and sincerely since their identities were kept secret.

b. Research process was explained clearly in order to increase external validity. The design of the research, study group, data collection process, and analysis and interpretation of the data were described in detail.

c. All of the data were written without any interpretation to ensure internal reliability. In addition, another faculty who has experience on qualitative research coded the information obtained from interviews. This code was compared with that of the researcher and the consistency was calculated (95\%).

d. Research process was explained clearly in order to increase external reliability. The raw data and coded data have been preserved by the researcher and other researchers are welcomed to examine them.

\subsubsection{Limitations}

There are several several limitations of this research. Firstly, the sample was one of volunteers and they are not necessarily representative of other teachers within other school types. Therefore, the results are limited to this group of teachers and caution should be exercised when attempting to infer about any of the results with regard to other populations. Secondly, the researcher was the main instrument of data analysis. The analyses and results are a product of the researcher's interpretation of the data. The study is the product of the researcher's perspective, and it is recognized that a different researcher may identify different features of importance within the same data sets (Bogdan \& Biklen, 1998; Creswell, 2002). Finally, although the researcher tried to look for equal gender representation, it was impossible because of the high willingness of male teachers.

\section{Results}

This study was conducted in order to determine the teachers' opinions on principal trust. In this part of the research, findings are given below:

\subsection{Trust in Principals as School Leaders}

It is believed that trust in school principal has a great influence on teachers' performance and work peace. If a teacher trusts his/her principal as an administrator, he has a tendency to feel secure and puts his/her effort on educational goals. It may also strengthen their organizational citizenship behaviors. Therefore; organizational policies towards school success may become true. One of the teachers, "I trust my school and I feel that he is 
trying his best to make our school a better place for all of us. I believe that if I have any problem, he will try to solve my problem. I also feel that I can be promoted fairly. He appreciates our efforts and gives the feeling that we are all equal at school. In some schools we hear that principals are problematic and autocratic. Fortunately, we are lucky in this manner (T5)."

Another teacher remarked, "We have a newly appointed principal and unfortunately he is more inexperienced than most of us here. This makes us feel irritated and we feel that he is not the right person to administer the school. In fact, we do not trust him fully as an administrator. He does not know what to do most of the time. He makes a lot of mistakes and he does not trust us, either (T6)."

A teacher claimed, "I am not sure if I should trust her or not. She is a newly-appointed principal. She has no experience in school administration. In her first meeting with us, she told us that she will learn how to administer a school here, which is not good. School is not a place for inexperienced principals to learn principalship by trial and error. How can you trust such a principal (T23)?"

Another teacher revealed, "Our principal is nice and kind person and he is trying to learn school administration. He has had no experience in school administration before, therefore, I do not trust him now. In fact, their way of appointment is wrong. The Ministry do not appoint the experienced ones. I feel that he will not be a good administrator. During the meetings, we, the teachers, understand that he does not know what to do. He does not give confidence as an administrator (T20)."

As can be understood from teachers' comments, in general teachers do not trust their principals as a school administrator. This may mean that there is a lack of trust in school settings. In fact, teachers want their principals to manage school effectively, behave fairly to all teachers, respect teachers and be competent in their roles. However, according to teachers' views, the situation is getting worse and worse day by day. The principals of this sample seem to be inexperienced. Some of whom do not have a single day administrative experience. For that reason, they do not think their principals are ideal person as a school administrator. As most of them are inexperienced as school administrator, they have a chance to make a lot of mistakes, which is a problem for schools today.

\subsection{Trust in Their Administrative Implementations}

Trust in school principal and his/her implementations are crucial in school environment. If teachers trust their principals, they can do their best and they can feel that they can be promoted by them. As far as trust in school principal implementations is concerned, a teacher claimed, "Trust in school principal's implementation affects teachers' practices. If teachers trust principals, school becomes a better place. In this case, our principal's implementations cannot be discussed. We want them to be effective and also fair in his daily practices. But we do not trust him here, because he does not have the capacity to manage a team of experienced teachers (T19)." Another teacher added, "I define trust in principals' implementations as being expert in his work and being as a mediator at school. Indeed, our principal is neither of them. He behaves as if he is our boss and he does not explain anything to any of us. He thinks that teachers are like his students and his implementations are in this direction. He has an autocratic management style (T3)."

However, a teacher stated, "Trust is not only related to only school principals, it is also related to teachers as well. As a newly-appointed principal, he is trying to do his best, but teachers think that a school principal cannot be an inexperienced one. They want principals who are competent and trustworthy. Of course, as an inexperienced principal, he is not competent, but we must give him a chance to show his abilities (T22). "Another teacher said, "For me a school principal should be fair. In our school, they have only their favorite teachers. They usually take care what the teachers around him say. When we say something different than their way of thinking, he rejects immediately. In this case, he does not give confidence to all of us. I feel alienated here. I sometimes think that the school is theirs and I feel isolated. He promotes those who are politically close to him. Once, he appointed one of our colleagues as a vice principal, but he was the last person to be appointed to that position. How can I trust my principal from now on? (T4)." One teacher remarked, "If I were the principal, I would communicate with the teachers better. I would behave them fairly. When academic issues are concerned, I noticed that our principal is very incompetent with managerial and academic issues. He has had no educational background on management. It is important, because it is our priority to conduct academic issues effectively. He cannot develop a vision and translate the mission to both the teachers and students. He behaves the students badly, he shouts at the corridors, and humiliates them mercilessly (T6)." A teacher said, "Our principal is fine in this manner. She is really nice, school-oriented, and a good communicator. She has a post graduate degree in educational administration and this makes her a better principal than the others I hear. She is always dealing with academic issues, and her first priority is to make our school a successful place. She is a fair one and she 
asks us, before she makes a critical decision. Therefore, we all trust our principal and her implementations at school (T28).”

Another teacher mentioned, "We are, as teachers of this school, basic values of this institution. We need to trust our principals. If there is no trust among the teachers and administrative team, no work can be done here. If we do not believe in what our principal can do, he cannot be successful, because teaching is a teamwork. Here, at our school we feel that there is a lack of trust among us. It is how we feel at our schools these days (T30)." Moreover, a teacher stated, "We do not have much trust in our principal at school. Therefore, things do not go smoothly. Now, it is the case. Most of the current principals are newly-appointed with some political considerations. In this process, the Ministry appointed inexperienced ones. Therefore, they do not know how to administer a school. In such an atmosphere, trust is a feeling that is strange for all of us. We do not know them very well (T7)." As one teacher put it, "Educational system wants us to be efficient at schools, but schools are the arena for policy makers to employ their fans these days. In the past, principals were experienced and managed school better. They were selected and appointed with an interview, which is mostly subjective. However, new principals are not aware of management, human resources and academic issues as well. We do not trust them because, they were appointed without looking at their competency. Most of them are incompetent in their positions (T21)."

As can be seen in teachers' comments, in general teachers do not trust their principals' administrative implementations on daily basis, which is considered as a problem by them as well. This may mean that as the principals are inexperienced as administrators, they are not aware of school administration. They were appointed to their posts without having been taken any in-service training in school administration. The teachers of this sample think that the principals are not related to academic issues. As they do not know how to cope with problems at schools, they have a tendency to believe what the people around them say. This means that they can be manipulated by the others easily. The teachers consider that teaching is a teamwork, and school principals do not have capacity to form teams and lead teams in accordance with school goals. In general, they are considered as incompetent in schools' administrative, human resources and leading the followers. They also think that most school principals should have a degree in educational administration and be appointed after some experience as vice administrator.

\subsection{Trust in Principals' Personality}

It is known that in order to stay be effective at schools, there should be trust among teachers and administrators. They are parts of a team, and team members should trust in each other. In such an atmosphere they can feel themselves valuable and secure. It is indicated that teachers' trust in school principal is the strongest predictor. A teacher alleged, "As teachers, we must focus on our work at school. We are not objects here. If teachers feel valuable and their needs are met, they can be successful here. Indeed, it seems that the principals are more valuable than us. During the meetings, principal dictates us his decisions and never cares about us. When we want to say something, he does not listen to us. We feel ourselves unimportant here. He is like a dictator (T13)."

Another teacher reported, "In fact, we are university graduates like him. We may have some better ideas. He wants us to respect him but his problematic personality makes us feel irritated, because he does not respect us. In fact, schools are more different than any of other institutions as we work with people. He has an authoritative personality type and therefore, I do not trust him (T1)."

According to a teacher, "It is essential to take care of the individual at school, because human factor is important here. I feel that we are not appreciated here. He is always behaving us as if he knows everything better than us. He carries out a duty, and we try to understand his responsibilities. However, no principal can be successful without teachers' total effort. Our principal does not share his authority and he is selfish. Therefore, we do not trust his personality. If I have any problem, I do not think I can share it with him (T4)." Another teacher mentioned, "School principals are not secure in this system. When they are not secure, this reflects to teachers. They are mostly stressed, because they do not want to upset those who appointed them. For this reason, they do care about the ones who will have a say to reappoint them. They do not care about teachers. This makes them different people as if they are politically oriented to some authorities. They do not know human relations, so they cannot manage human resources at school. They are politically sided (T8)." A teacher affirmed, "As a teacher, we think schools are unsafe, I feel uncomfortable and restless. School principals some behaviors make us feel such that. They are not trustworthy (T7)." Another teacher expressed, "Focusing on individuals by valuing their personal sides primarily may help things to go better at a school. Personally, I think school principals are selfish most of the time. They do not respect us, and our principal is disrespectful sometimes (T5)." 
Schools are key places for societies. The teachers and administrators are role models at the same time. Therefore, they should be personally trustworthy, reliable and sincere, because both students and teachers feel they must trust. Sometimes, they tell their secrets to their teachers and principals. As can be inferred from the teachers' comments, in general teachers do not trust their principals' personalities as well. This may mean that as the principals are quite young and professionally inexperienced as administrators, they are not aware of human relations as well. Human relations play significant roles in a school. They are also behaving in an authoritative way. They have a tendency to take decisions without asking teachers during the meetings. Hence, teachers have expertise in their fields and some teachers are more experienced than them. This may lead to distrust among teachers and they may not be perceiving themselves valuable at school. Furthermore, some of the principals of this sample have disrespectful behaviors towards teachers at school and they are considered as selfish from time to time. Sometimes they do not care about teachers.

\section{Discussion}

Many studies reveal that there is a strong relationships between teacher trust in school principal and better performance at schools (Bryk \& Schneider, 2003; Hoy \& Tarter, 2004; Marks \& Printy, 2003; Louis, 2007; Tschannen-Moran \& Hoy, 1998). Therefore, this study researched teachers' trust in school principals in terms of as trust in their principals as school leaders, their administrative implementations and their principals' personality in the Turkish educational context and some results were obtained.

As far as teachers' perceptions on trust in principals as school leaders are concerned, in general, the teachers' opinions are mostly negative. As can be seen their statements above, there is a lack of trust in them as leaders. Leaders are the ones who lead, develop academic standards, motivate, inspire the followers, set vison and translate this mission to the staff and students. They can realize these roles with their intellectual capacity and charisma. This shows that teachers of this sample do not consider their principals as the leaders who will perform these roles. This may stem from their selection criteria and appointment process, which does not care about some basic qualities and qualifications such as having education in the field of educational administration and experience in school administration. In the last few years, there have been political considerations which intervene school pace and peace very often in Turkey. Teachers of this sample may be considering that the school principals are not the leaders to trust in, which is problematic for any school system as well as the Turkish educational context. In such a school culture, the work of school administration is perceived as a kind of work that any teacher can perform. Experience and education in school administration is not asked from the principal candidates. Therefore, the system is becoming weak and conditions are going bad. More specially, teaching is a teamwork and school principals are supposed to be the leaders of these teams. Since they are believed to be incompetent as leaders, they cannot form and lead teams in an effective way accordingly. This may cause new and complicated problems among teachers. Moreover, as they cannot manage teachers successfully, they try to suppress the whole group during the meetings, because teachers are more experienced and principals may perceive this as a threat for their positions. It is also understood from their statements that teachers are willing to participate in decisions; however, they claim that school principals do not want teachers to participate in the decisions. For that reason, they have a tendency to take decisions on their own without asking the others. This is probably because of their lack of experience in school administration. It is also considered that they have characteristics of classical management approach, they may not desire to share the management power with the others, but it is considered that teachers are important parts of a school and they have expertise to take part in decisions. In order to provide to create a positive school climate for both teachers and students, the administrators should change their way of behavior. Yet, some studies found a link between faculty trust and a positive school climate (Hoffman, Sabo, Bliss, \& Hoy, 1994; Hoy, Sabo, \& Barnes, 1996; Hoy, Tarter, \& Kottkamp, 1991; Tarter, Bliss, \& Hoy, 1989; Tarter, Sabo, \& Hoy, 1995). In another study, according to Goddard, Tschannen-Moran, and Hoy $(2007,2001)$ trust makes schools better places for students to learn and teachers to teach.

A further result shows that most of the teachers of this sample do not trust in their principals' daily administrative implementations. In this regard, teachers claim that current principals most of whom were newly-appointed with a quick political decision are incompetent in school administration field. In other words, they are inexperienced in their posts and they have not taken any course or in-service training in school administration, therefore; they are not effective at schools. Among them, some do not have a single day administrative experience in the school system. For this reason, they believe that these inexperienced principals do not know how to manage schools and human resources there. As a result of this, most of them may have a possibility to make a lot of mistakes in their daily administrative practices, which may lead to student failure and teacher dissatisfaction. Hence, many studies find significant relationships between organizational trust perceptions of teachers and student outcomes (Bas, 
2012; Mitchell, Kensler, \& Tschannen-Moran, 2010; Tschannen-Moran, 2009). In the last few years, the Turkish Ministry of Education had a quick decision and removed 8 thousand school principals at one night. By removing experienced principals from their posts, they appointed new ones who were not asked any experience in the field of school administration. According to the new regulations, school principals are employed in their posts for four years. After that period, their contracts cannot be renewed if they are not evaluated as efficient by the Ministry authorities with some interviews, which are claimed to be mostly subjective. Teachers remark that since school principals were appointed to their posts with political considerations ignoring scientific and objective criteria, they may try to do things what politicians like to see instead of academic considerations. This may lead to negligence in academic issues and students as well as parents in school environment. Moreover, teachers do not trust in their expertise in academic issues as well as administrative concerns. Indeed, as having post graduate degree in educational administration field is not required in the current system, most of them do not have qualities and qualifications needed at a school. Despite this, they are not taken to any in-service training, which would help them develop their administrative qualities and qualifications. Since they are not accepted as competent in their positions, too, they make a lot of mistakes in their administrative practices on daily basis. In fact, they do not know how to behave in certain situations. In addition, they can also have problems with managing school staff and teachers. Because of the fact that they do not know rules and regulations well, they can easily be manipulated by their vice principals.

When the principals' personalities are concerned, teachers of this sample find their principals rather autocratic, sometimes disrespectful, selfish and unreliable. This is an important problem at schools, because schools are human communities and respect is an essential element there. This is probably because of the fact that the principals are not educated in the field of educational administration, they may not care about human relations there. Consequently, result shows that teachers show low level of trust at school in general. When teachers do not trust in their principals at schools, they feel they are not valuable at their schools. This might stem from the centrally-controlled body of the ministry that appoints inexperienced principals to schools without considering such practical problems. In a centrally-managed body, lack of democracy and conditions, teachers may not express themselves properly and contribute to school goals. In the long term, this may lead to disengagement among teachers. According to organizational theorists, principals' behavior on the part of leaders will motivate teachers to go beyond their formally prescribed job responsibilities and to give their very best to the task. Trust in the principal was found to be a predictor of organizational citizenship behaviors (Tschannen-Moran, 2003).

In conclusion, teachers tend to trust in principals who motivate them, encourage participation in school-related decisions, encourage them towards self-development, and make them feel that they are respected. Therefore, principals should foster collective vision, model for desired and appropriate behaviors, coach faculty to empower their skills, manage organizational resources fairly and skillfully, and mediate conflicts that may emerge in the complex work of schooling (Tschannen-Moran, 2004a, 2007; Tschannen-Moran \& Gareis, 2015). In order to conduct these roles, they should be experienced in school administration and reassuring. For this reason, Demir (2015) puts that trust should be fostered, authenticity and integrity should be basic concerns, and schools should be led with a collegial leadership style. The recommendations reached through the results obtained in this study and implications for further research and practice are below:

- Educational system in Turkey is very centralized. School principals are appointed to their posts centrally with some subjective decisions. This situation can be improved by setting scientific and objective criteria to appoint qualified ones.

- The principals can be asked degrees in educational administration and experience in school management at least 5 years as assistant principal or principal.

- As most school principals are inexperienced, they do not know school administration and human resources management well, which may cause distrust among teachers. This problem can be solved by training them in school administration with in-service trainings and seminars beforehand.

\section{References}

Bas, G. (2012). Correlation between school principals' instructional leadership behaviors and teachers' organizational trust perceptions. Middle Eastern \& African Journal of Educational Research, 1(Fall), 5-18.

Bass, B. M., \& Riggio, R. E. (2006). Transformational leadership. Lawrence Erlbaum Associates, Inc., Publishers.

Bogdan, R. C., \& Biklen, S. K. (1998). Qualitative research for education: An introduction to theory and methods (3rd ed.). Boston, MA: Allyn \& Bacon. 
Bryk, A. S., \& Schneider, B. (2002). Trust in schools: A core resource for improvement. New York, NY: Russell Sage Foundation.

Bryk, A. S., \& Schneider, B. (2003). Trust in schools: A core resource for school reform. Educational Leadership, $60(6), 40-45$.

Creswell, J. W. (2002). Educational research: Planning, conducting, and evaluating quantitative and qualitative research. Upper Saddle River, New Jersey: Merrill Prentice Hall.

Daly, J. A. (2009). Rigid response in an age of accountability the potential of leadership and trust. Educational Administration Quarterly, 45(2), 168-216. https://doi.org/10.1177/0013161X08330499

Demir, K. (2015). The effect of organizational trust on the culture of teacher leadership in primary schools. Educational Sciences: Theory \& Practice, 15(3), 621-634. https://doi.org/10.12738/estp.2015.3.2337

Denzin, N. K., \& Lincoln, Y. S. (2005). The sage handbook of qualitative research (3rd ed.). Sage, Thousand Oaks.

Dirks, K. T., \& Ferrin, D. L. (2002). Trust in leadership: Meta-analytic findings and implications for research and practice. Journal of Applied Psychology, 87(4), 611-628. https://doi.org/10.1037/0021-9010.87.4.611

Feixas, G., \& Cornejo-Alvarez, J. M. (2002). A manual for the repertory grid: Using the GRIDCOR programme (version 4.0). Retrieved December, 26, 2016, from http://www.terapiacognitiva.net/record/pag/index.htm

Gillespie, N. A., \& Mann, L. (2004). Transformational leadership and shared values: The building blocks of trust. Journal of Managerial Psychology, 19(6), 588-607. https://doi.org/10.1108/02683940410551507

Goddard, R. D., Tschannen-Moran, M., \& Hoy, W. K. (2007). A multilevel examination of the distribution and effects of teacher trust in students and parents in urban elementary schools. In W. K. Hoy, \& M. F. DiPaola (Eds.), Essential Ideas for Reform of American Schools (pp. 115-136). Greenwich, CT: Information Age Publishing.

Hoffman, J., Sabo, D., Bliss, J., \& Hoy, W. K. (1994). Building a culture of trust. Journal of School Leadership, $4(9), 484-501$.

Hoy, K. W., \& Tarter, C. J. (2004). Organizational justice in schools: No justice without trust. International Journal of Educational Management, 18(4), 250-259. https://doi.org/10.1108/09513540410538831

Hoy, W. K., \& Kupersmith, W. J. (1985). The meaning and measure of faulty trust. Educational and Psychological Research, 5, 1-10.

Hoy, W. K., \& Tschannen-Moran, M. (1999). The five faces of trust: An empirical confirmation in urban elementary schools. Journal of School Leadership, 9, 184-208.

Hoy, W. K., \& Tschannen-Moran, M. (2003). The conceptualization and measurement of faculty trust in schools: The omnibus T-Scale. In W. K. Hoy, \& C. G. Miskel (Eds.), Studies in Leading and Organizing Schools (pp. 181-208). Information Age Publishing: Greenwich: CT.

Hoy, W. K., Sabo, D., \& Barnes, K. (1996). Organizational health and faculty trust: A view from the middle level. Research in Middle Level Education Quarterly, Spring, 21-39.

Hoy, W. K., Tarter, C. J., \& Kottkamp, R. B. (1991). Open schools, healthy schools: Measuring organizational climate. Newbury Park, CA: Sage.

Jung, D. I., \& Avolio, B. J. (2000). Opening the black box: An experimental investigation of the mediating effects of trust and value congruence on transformational and transactional leadership. Journal of Organizational Behaviour, 21, 949-964. https://doi.org/10.1002/1099-1379(200012)21:8\%3C949::AID-JOB64\%3E3.0.CO;2-F

Kerkhof, van de M. (2006). The repertory grid technique (RGT), integrated assessment. Retrieved June 26, 2015, from http://www.ivm.vu.nl/en/Images/PT4_tcm53-161509.pdf

Louis, K. S. (2007). Trust and improvement in schools. Journal of Education Change, 8(1), 1-24. https://doi.org/10.1007/s10833-006-9015-5

Marks, H. M., \& Printy, S. M. (2003). Leadership principal leadership and school performance: An integration of transformational and instructional leadership. Educational Administration Quarterly, 39(3), 370-397. https://doi.org/10.1177/0013161X03253412 
Marlowe, H. A. Jr., \& Nyhan, R. C. (1997). Development and psychometric properties of the organizational trust inventory. Evaluation Review, 21(5), 614-635. https://doi.org/10.1177/0193841X9702100505

Marshall, C., \& Rossman, B. G. (2006). Designing qualitative research (4th ed.). Thousand Oaks: Sage Publication.

Mayring, P. (2000). Qualitative content analysis. Forum: Qualitative Social Research, 1(2). Retrieved December 26, 2012, from http://217.160.35.246/fqs-texte/2-00/2- 00mayring-e.pdf

Mitchell, R. M., Kensler, L., \& TschannenMoran, M. (2010). The role of trust and school safety in fostering Identification with School. Paper presented at the annual meeting of the University Council for Educational Administration, New Orleans, LA.

Ngodo, O. E. (2008). Procedural Justice and trust: The link in the transformational leadership-organizational outcomes relationship. International Journal of Leadership Studies, 4(1), 82-100.

Pillai, R., Schriesheim, C., \& Williams, E. (1999). Fairness perceptions and trust as mediators for transformational and transactional leadership: A two-sample study. Journal of Management, 6, 897-933. https://doi.org/10.1177/014920639902500606

Podsakoff, P. M., MacKenzie, S. B., Moorman, R. H., \& Fetter, R. (1990). Transformational leader behaviours and their effects on followers' trust in leader, satisfaction, and organizational citizenship behaviours. Leadership Quarterly, 1(2), 107-142. https://doi.org/10.1016/1048-9843(90)90009-7

Tarter, C. J., Bliss, J. R., \& Hoy, W. K. (1989). School characteristics and faculty trust in secondary schools. Educational Administration Quarterly, 25(3), 294-308. https://doi.org/10.1177/0013161X89025003005

Tarter, C. J., Sabo, D., \& Hoy, W. K. (1995). Middle school climate, faculty trust, and effectiveness: A path analysis. Journal of Research and Development in Education, 29, 41-49.

Tschannen-Moran, M. (2003). Fostering organizational citizenship: Transformational leadership and trust. In W. K. Hoy, \& C. G. Miskel (Eds.), Studies in Leading and Organizing Schools (pp. 157-179). Greenwich, CT: Information Age Publishing.

Tschannen-Moran, M. (2004a). Trust Matters: Leadership for Successful Schools. San Francisco: Jossey-Bass.

Tschannen-Moran, M. (2007). Becoming a trustworthy leader. In The Jossey-Bass Reader on Educational Leadership (2nd ed.). San Francisco: Jossey Bass.

Tschannen-Moran, M. (2009). Fostering teacher professionalism: The role of professional orientation and trust. Educational Administration Quarterly, 45, 217-247. https://doi.org/10.1177/0013161X08330501

Tschannen-Moran, M., \& Gareis, C. R. (2015). Principals, trust, and cultivating vibrant schools. Societies, 5 , 256-276. https://doi.org/10.3390/soc5020256

Tschannen-Moran, M., \& Goddard, R. (2001). Collective efficacy and trust: A multilevel analysis. Paper presented at the annual meeting of the American Educational Research Association, Seattle, WA.

Tschannen-Moran, M., \& Hoy, W. K. (1998). Trust in schools: A conceptual and empirical analysis. Journal of Educational Administration, 36, 334-352. https://doi.org/10.1108/09578239810211518

Zeinabadi, H., \& Rastegarpour, H. (2010). Factors affecting teacher trust in principal: Testing the effect of transformational leadership and procedural justice. Procedia Social and Behavioral Sciences, 5, 1004-1008. https://doi.org/10.1016/j.sbspro.2010.07.226

\section{Copyrights}

Copyright for this article is retained by the author(s), with first publication rights granted to the journal.

This is an open-access article distributed under the terms and conditions of the Creative Commons Attribution license (http://creativecommons.org/licenses/by/4.0/). 